\title{
Organic Solvent Use in Research Institutions in Japan
}

\author{
Yasuhiro NAGASAWA ${ }^{1}$, Hirohiko UKAI ${ }^{1}$, Satoru OKAMOTO ${ }^{1}$, Hajime SAMOTO¹, \\ Kenji ITOH $^{1}$, Jiro MORIGUCHI ${ }^{2}$, Sonoko SAKURAGI ${ }^{2}$, Fumiko OHASHI ${ }^{1}$, \\ Shiro TAKADA ${ }^{1}$, Takuya KAWAKAMI ${ }^{1}$ and Masayuki IKEDA ${ }^{1 *}$ \\ ${ }^{1}$ Kyoto Industrial Health Association (Main Office), 67 Nishinokyo-Kitatsuboicho, Nakagyo-ku, Kyoto \\ 604-8472, Japan \\ ${ }^{2}$ Kyoto Industrial Health Association (Mibu Office), 4-1 Mibu-Shujaku-cho, Nakagyo-ku, Kyoto 604-8871, \\ Japan
}

Received August 4, 2010 and accepted December 28, 2010

Published online in J-STAGE June 21, 2011

\begin{abstract}
In 2008-2009, types of organic solvents used and air-borne vapor concentrations were surveyed in 1909 laboratories in four large research institutions in accordance with current regulations. The results were classified into 5 groups in terms of research fields (agriculture, biology, medicine, natural science, and technology and engineering) and evaluated after the regulatory rules. Laboratory air analyses by gas chromatography identified 5 and 20 solvents out of 7 Group 1 solvents and 40 Group 2 solvents, respectively; 10 solvents were used in more than $10 \%$ of the laboratories in each of the 5 research fields. The use of unmixed single solvent appeared to be unique in research laboratories in contrast to use of solvent mixtures in industrial facilities for production. Laboratories of technology and engineering fields used more various organic solvents more frequently, whereas use of xylenes appeared to be more specific to laboratories of bio-medical fields. Among the commonly used solvents, chloroform was the leading solvent to induce poorer results in regulatory classification (i.e., Class 3 in Administrative Control Classes) typically when applied in high pressure liquid chromatography which was too voluminous to be accommodated in a local exhaustion chamber.
\end{abstract}

Key words: Organic solvent, Research laboratory, Unmixed solvent, Use pattern

\section{Introduction}

Regulatory basis for maintenance of laboratory conditions in various public (non-private) research institutions has been transferred in 2004 to Industrial Safety and Health Law ${ }^{1,2)}$. This transfer offered pressing opportunities to both institution administrations and research staff to reconsider the exposures of the research staff (including under- and post-graduate students) to various chemicals such as organic solvents (to be called solvents in short $)^{3)}$. The importance of establishing net-work for occupational health activities among universities has been also stressed for mutual exchange of information ${ }^{4}$.

*To whom correspondence should be addressed.

E-mail: ikeda@hokenkai.jp
Solvents have been widely used in many laboratories of various scientific disciplines. Accordingly, it was considered important to evaluate the types of solvents and the exposure intensities in reference to the regulatory ordinance for prevention of solvent poisoning 5 ).

In the present study, four large research institutions were investigated for solvent exposure in laboratories of various fields of science. Efforts were made to identify characteristic nature (if present) of solvent exposures in research laboratories in comparison with the exposure in industries.

\section{Materials and Methods}

Research laboratories in institutions surveyed

Four research institutions were surveyed during a 
Table 1. Laboratories surveyed and solvents detected by research fields

\begin{tabular}{|c|c|c|c|c|c|c|c|}
\hline & \multicolumn{6}{|c|}{ Laboratories } & \multirow{2}{*}{$\begin{array}{c}p \text { by } \chi^{2} \\
\text { test }\end{array}$} \\
\hline & AGR & BIOL & MED & SCI & $\mathrm{T} \& \mathrm{E}$ & Total & \\
\hline No. of laboratories & 284 & 358 & 559 & 374 & 334 & 1,909 & \\
\hline \multicolumn{8}{|l|}{ Organic solvents ${ }^{\mathrm{b}}$} \\
\hline Group 1 & 2 & 4 & 2 & 3 & 5 & 5 & \\
\hline Group 2 & 18 & 21 & 17 & 22 & 21 & 28 & \\
\hline Sum & 20 & 25 & 19 & 25 & 26 & 33 & $>0.10$ \\
\hline$\%^{c}$ & 42.6 & 53.2 & 40.4 & 53.2 & 55.3 & 70.2 & \\
\hline
\end{tabular}

${ }^{a} \mathrm{AGR}, \mathrm{BIOL}, \mathrm{MED}, \mathrm{SCI}$ and T\&E stand for agricultural, biology (other than medicine), medical, science and engineering and technology laboratories, respectively.

${ }^{\mathrm{b}}$ The total number of kinds of solvents in the ordinance is 7 for Group 1 and 40 for Group 2, or 47 as combined.

'Percentage over 47 cases.

two-year-period from April, 2008 to March, 2010. Each of them had research staff in excess of 1,000 persons. The research fields were classified into agricultural (AGR), biological (BIOL, excluding medicine), medical (MED, including hospitals), natural science (SCI, mostly chemistry), and technology and engineering (T\&E).

While the regulation requests that each institutions be surveyed every six months ${ }^{4}$, the latest results were filed to avoid duplication. In practice, a total of 1,909 laboratories were surveyed (the top half in Table 1), irrespective of size (space) of each laboratory. Although a typical laboratory had a space of about $3 \mathrm{~m}$ by about $6 \mathrm{~m}$, a smaller one was attended just by one person, whereas a largeer one accommodated well in excess of 30 people.

Analyses of solvent vapor and evaluation of the results

The target solvents were Group 1 (7 solvents) and Group 2 (40 solvents) as prescribed by the ordinance for prevention of solvent poisoning ${ }^{5)}$ and listed in a previous publication; Group 3 solvents were not taken into account as they are natural solvent mixtures ${ }^{5,6)}$. The methods of air sampling (by the Tedlar bag method) and instrumental analyses (by capillary gas-chromatography) were in accordance with regulatory standards also as previously described in details ${ }^{6}$. The measurement results were evaluated in reference to administrative evaluation standards including the 1st July, 2009 amendment of Administrative Control Levels [i.e., carbon disulfide $1 \mathrm{ppm}$ (previously $10 \mathrm{ppm}$ ), chloroform 3 (10) ppm, cyclohexanone 20 (25) ppm, tetrahydrofurane 50 (200) ppm, toluene 20 (50) ppm, trichloroethylene $10(25) \mathrm{ppm}]^{7)}$; the additiveness formula ${ }^{9)}$ was applied when two or more solvents were simultaneously detected. The results were classified into three levels of Administrative Control Class 1 (the well controlled environment), 2 (the intermediary environment) and 3 (the environment which requires immediate and sufficient improvement ${ }^{10)}$.

\section{Statistical analyses}

$\chi^{2}$ test was employed to detect possible difference in distribution.

\section{Results}

\section{Typical pattern of solvent use}

Numbers of solvents detected in each laboratory in various research fields are graphically presented in Fig. 1. It is clear from the figure that only one solvent was detected in majorities of laboratories irrespective of research fields (i.e., in 40 to $60 \%$ ). Observation in laboratories indicated that each researcher usually used just one solvent for one work (e.g., dissolving, extraction etc.). Thus the presence of more than one solvent in laboratory air was due to use of several solvents in sequence by one researcher or simultaneous use of various solvents by more than one researcher in a single laboratory.

\section{Types of solvents detected}

The number of types of solvents detected is listed in the bottom half of Table 1 by the ordinance-based groups of solvents and by research fields of laboratories. Both groups of solvents were used in all fields of research; when classified by the group, 5 solvents out of 7 and 28 solvents out of 40 were detected in Group 1 and Group 2, or 33 solvents out of 47 when combined. Comparison by the research fields revealed that less variety $(p<0.01)$ of solvents were used in AGR $(20 / 47=42.6 \%)$ and MED (40.4\%) than in BIOL, SCI and T\&E (53.2-55.3\%).

Among the 7 Group 1 solvents, use of chloroform was common throughout the five fields $(34.6 \%$ in BIOL to $53.2 \%$ in AGR) whereas it was less frequent for remaining 6 solvents. When the prevalence of chlo- 


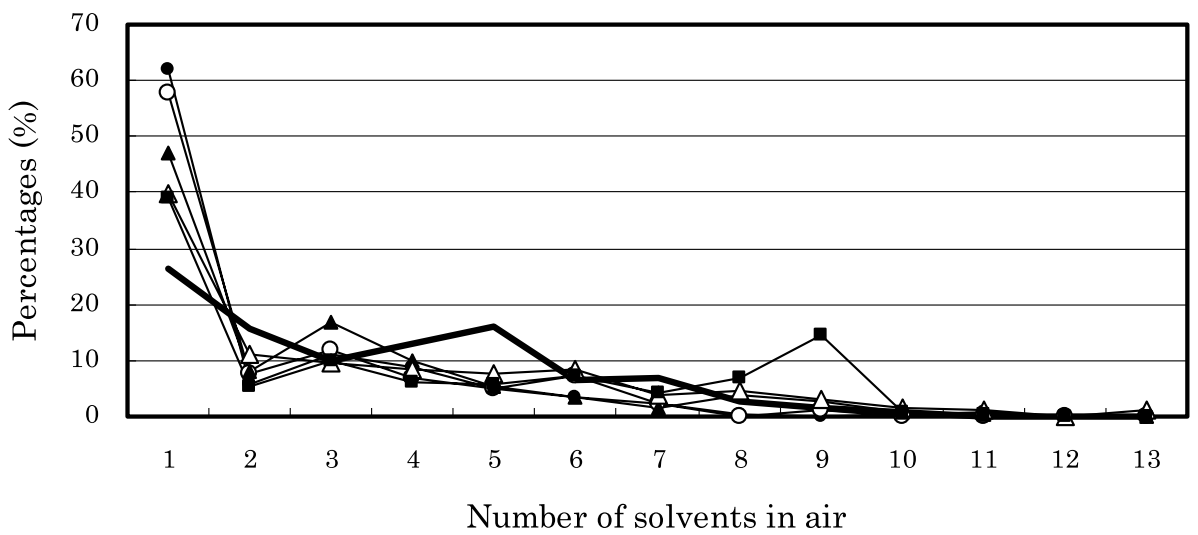

Fig. 1. Number of solvents detected in air by research fields.

Percentages are depicted on the vertical axis, taking numbers of laboratories as 100. Symbols for research fields are: Solid circles ( $\bigcirc$ ) for MED; open circles ( $\bigcirc$ ) for BIOL; solid triangles ( $\boldsymbol{\Delta}$ ) for AGR; open triangles $(\triangle$ ) for SCI; solid squares ( $\square$ ) for T\&E; no mark with thick lines for general industries (cited from Ref. 6).

Table 2. Solvents used in various faculties; Group 1 solvents

\begin{tabular}{|c|c|c|c|c|c|c|c|}
\hline \multirow{2}{*}{ Group 1 solvents $^{\mathrm{a}}$} & \multicolumn{6}{|c|}{ Laboratories $^{\mathrm{b}}$} & \multirow{2}{*}{$\begin{array}{c}p \text { by } \chi^{2} \\
\text { test }^{\mathrm{c}}\end{array}$} \\
\hline & AGR & BIOL & MED & $\mathrm{SCI}$ & $\mathrm{T} \& \mathrm{E}$ & Total & \\
\hline Carbon disulfide & 0.0 & 0.3 & 0.0 & 0.0 & 0.6 & 0.2 & na \\
\hline Carbon tetrachloride & 0.0 & 0.8 & 0.0 & 2.4 & 1.2 & 0.8 & na \\
\hline Chloroform & 53.2 & 34.6 & 37.4 & 42.0 & 44.9 & 41.4 & $* *$ \\
\hline Dichloroethane, 1,2- & 1.1 & 0.0 & 0.0 & 0.5 & 11.1 & 2.2 & na \\
\hline Trichloroethylene & 0.0 & 0.6 & 0.2 & 0.0 & 0.9 & 0.3 & na \\
\hline
\end{tabular}

${ }^{\mathrm{a}}$ Group 1 solvents in the ordinance consist of 7 selvents, of which 5 solvents detected are listed.

bAbbreviations for research fields are as under Table 1.

c**, $p<0.01 ;$ na, not applicable due to small number of cases.

roform use was compared, the use in AGR was more prevalent than any other four $(p<0.01$; Table 2$)$.

With regard to the uses of Group 2 solvents, 28 solvents were detected among the 40 solvents in the group. Furthermore the prevalence was not uniform among the 28 solvents. Eighteen solvents were used in less than 5 laboratories so that $\chi^{2}$ test was not applicable for prevalence comparison among the 5 research fields [i.e., cases marked with 'na' (not applicable) in the rightmost column in Table 3]. Among the remaining 10 solvents for which sufficient number of cases was available for inter-field comparison, a bias in the prevalence $(p<0.01)$ was observed for 8 solvents of acetone (with highest prevalence of $63.5 \%$ in $\mathrm{T} \& \mathrm{E}$ ), dichloromethane (35.6\% in T\&E), ethyl acetate (38.0\% in T\&E), hexane (47.9\% in T\&E), isopropyl alcohol (33.6\% in MED), methanol $(56.4 \%$ in SCI) toluene $(36.2 \%$ in T\&E) and xylenes (32.2\% in MED). No significant bias $(p>0.10$; cases marked with 'NS' in the right-most column in Table 3) in use prevalence was detected for $N, N$ dimethylformamide (3.9\% in AGR to $8.8 \%$ in SCI) or ethyl ether (15.9\% in BIOL to $20.9 \%$ in MED).
It should be noted that several solvents were not detected in the present survey. Such solvents are listed in Table 4 by solvent groups; i.e., two solvents in Group 1 and 12 solvents in Group 2.

\section{Common use of solvents by research fields}

By comparing the use prevalence among the 5 research fields, it was possible to summarize several characteristic use patterns of solvents among the 5 research fields. Use of solvents was most common in T\&E fields (Tables 1, 2 and 3), especially for dichloromethane, ethyl acetate, hexane and toluene, with one exception of isopropyl alcohol.

With regard to individual solvents, use of acetone (26.7-63.5\%), isopropyl alcohol (13.5-33.6\%) and methanol $(43.5-56.4 \%)$ is frequent in all of the 5 research fields, although the prevalence was not even among the fields (Table 3). Observation in laboratories revealed that these solvents were popularly used for rapid desiccation by spraying over an inner surface of a waterwashed container or vessel, more so for acetone in T\&E, for isopropyl alcohol in MED (possibly coupled 
Table 3. Solvents used in various faculties; Group 2 solvents

\begin{tabular}{|c|c|c|c|c|c|c|c|}
\hline \multirow{2}{*}{ Group 2 solvents ${ }^{\mathrm{a}}$} & \multicolumn{6}{|c|}{ Laboratories ${ }^{\mathrm{b}}$} & \multirow{2}{*}{$\begin{array}{c}p \text { by } \chi^{2} \\
\text { test }^{\mathrm{c}}\end{array}$} \\
\hline & AGR & $\mathrm{BIOL}$ & MED & SCI & $\mathrm{T} \& \mathrm{E}$ & Total & \\
\hline Acetone & 31.3 & 35.2 & 26.7 & 54.8 & 63.5 & 40.9 & $* *$ \\
\hline Butanol, 1- & 6.3 & 5.0 & 5.4 & 3.7 & 0.3 & 4.2 & na \\
\hline Butanol, 2- & 0.4 & 0.3 & 0.2 & 0.5 & 0.3 & 0.3 & na \\
\hline Butyl acetate, $n$ - & 0.7 & 0.0 & 0.0 & 0.5 & 0.0 & 0.2 & na \\
\hline Cellosolve $^{\mathrm{d}}$ & 0.4 & 0.0 & 0.0 & 0.0 & 0.0 & 0.1 & na \\
\hline Chlorobenzene & 0.0 & 0.0 & 0.0 & 0.3 & 0.6 & 0.2 & na \\
\hline Cresols & 0.0 & 0.0 & 0.2 & 1.3 & 0.0 & 0.3 & na \\
\hline Cyclohexanone & 0.0 & 0.6 & 0.0 & 0.5 & 0.3 & 0.3 & na \\
\hline Dichlorobenzene, $o$ - & 0.0 & 0.0 & 0.0 & 0.3 & 0.0 & 0.1 & na \\
\hline Dichloromethane & 7.4 & 3.1 & 1.1 & 17.4 & 35.6 & 11.6 & $* *$ \\
\hline Dimethylformamide, $N, N$ - & 3.9 & 6.7 & 5.9 & 8.8 & 8.7 & 6.8 & NS \\
\hline Dioxane, 1,4- & 0.7 & 0.6 & 0.0 & 0.0 & 1.2 & 0.4 & na \\
\hline Ethyl acetate & 18.7 & 13.1 & 2.3 & 26.2 & 38.0 & 17.7 & $* *$ \\
\hline Ethyl ether & 20.8 & 15.9 & 20.9 & 19.8 & 18.0 & 19.2 & NS \\
\hline Hexane & 21.5 & 14.5 & 4.8 & 26.5 & 47.9 & 20.9 & $* *$ \\
\hline Isoamyl acetate & 0.7 & 0.8 & 0.2 & 0.0 & 0.0 & 0.3 & na \\
\hline Isoamyl alcohol & 2.5 & 1.4 & 1.6 & 2.9 & 0.9 & 1.8 & na \\
\hline Isobutyl acetate & 0.0 & 0.3 & 0.0 & 0.0 & 0.0 & 0.1 & na \\
\hline Isobutyl alcohol & 0.0 & 0.0 & 0.2 & 0.8 & 0.0 & 0.2 & na \\
\hline Isopropyl alcohol & 29.2 & 27.1 & 33.6 & 29.1 & 13.5 & 27.3 & $* *$ \\
\hline Methanol & 51.1 & 49.4 & 43.5 & 56.4 & 50.0 & 49.4 & $* *$ \\
\hline Methyl acetate & 0.0 & 0.8 & 0.0 & 0.0 & 0.3 & 0.2 & na \\
\hline Methyl ethyl ketone & 0.0 & 0.8 & 0.0 & 0.8 & 0.6 & 0.4 & na \\
\hline Methyl isobutyl ketone & 0.0 & 0.6 & 0.0 & 0.0 & 0.3 & 0.2 & na \\
\hline Styrene & 0.0 & 0.3 & 0.0 & 2.4 & 0.6 & 0.6 & na \\
\hline Tetrahydrofuran & 8.1 & 0.0 & 0.7 & 12.3 & 16.2 & 6.7 & na \\
\hline Toluene & 10.9 & 6.1 & 3.6 & 23.0 & 36.2 & 14.7 & $* *$ \\
\hline Xylenes & 9.5 & 12.0 & 32.2 & 13.9 & 12.0 & 17.9 & $* *$ \\
\hline
\end{tabular}

${ }^{\mathrm{a}}$ Group 2 solvents in the ordinance consist of 40 solvents, of which only those detected are listed.

${ }^{\mathrm{b}}$ Abbreviations for research fields are as under Table 1.

$\mathrm{c} * *, p<0.01$; NS, not significant $(p \geq 0.05)$; na, not applicable due to small number of cases.

${ }^{\mathrm{d}}$ Ethylene glocol monoethyl ether.

Table 4. Organic solvents which were not detected $^{\mathrm{a}}$

\begin{tabular}{ll}
\hline Group & Organic solvents \\
\hline Group 1 & Carbon tetrachloride \\
& Tetrachloroethane, 1,1,2,2- \\
Group 2 & Amyl acetate \\
& Butyl cellosolve $^{\mathrm{b}}$ \\
& Cellosolve acetate $^{\mathrm{c}}$ \\
& Cyclohexanol $^{\text {Isopropyl acetate }}$ \\
& Methyl butyl ketone \\
& Methyl cellosolve \\
& Methylcyclohexanol \\
& Methylcyclohexanone \\
& Propyl acetate \\
& Tetrachloroethylene \\
& Trichloroethane, 1,1,1-
\end{tabular}

arganic solvents which are listed in the ordinance but not detected in the present survey.

${ }^{b}$ Ethylene glycol monobutyl ether.

${ }^{\mathrm{c} E t h y l e n e ~ g l y c o l ~ m o n o e t h y l ~ e t h e r ~ a c e t a t e . ~}$

${ }^{\mathrm{d}}$ Ethylene glycol monomethyl ether. with aim of disinfection), and for methanol in SCI.

Popular use of xylenes was characteristic to MED (32.2\%; Table 3). This solvent (predominantly $m$-xylene) was used for removal of paraffin from paraffin-embedded tissue slice in histology preparation work. Such work was also practiced in some laboratories in $\mathrm{BIOL}$ and SCI.

\section{Evaluation of laboratory environments}

When the results of the solvent level measurements were evaluated in reference to the regulatory evaluation system in combination with the latest amendments (for details, see the Materials and Methods section above), a majority $(98.5 \%$ for total and $96.1 \%$ for $\mathrm{T} \& \mathrm{E}$ as the lowest) cleared the regulation irrespective of research fields (Table 5), being identified in Class $1^{7)}$. Analyses of the cases in Classes 2 and 3 showed that the combination of the two classes as the cases of inadequate environments accounted for $1.5 \%$ of the total 1,909 
Table 5. Laboratories of inadequate environment

\begin{tabular}{|c|c|c|c|c|c|c|c|c|c|c|}
\hline \multirow[b]{2}{*}{ Research fields } & \multirow[b]{2}{*}{ Total cases } & \multirow[b]{2}{*}{$(\%)$} & \multicolumn{8}{|c|}{ Administrative control classes ${ }^{\mathrm{a}}$ (No. of cases) } \\
\hline & & & \multicolumn{2}{|c|}{$\begin{array}{r}\text { Class } 1 \\
(\%)\end{array}$} & \multicolumn{2}{|c|}{$\begin{array}{r}\text { Class } 2 \\
(\%)\end{array}$} & \multicolumn{2}{|c|}{$\begin{array}{r}\text { Class } 3 \\
(\%)\end{array}$} & \multicolumn{2}{|c|}{$\begin{array}{r}\text { Classes } 2+3 \\
(\%)\end{array}$} \\
\hline AGR & 284 & $(14.9)$ & 281 & $(98.9)$ & 2 & $(0.7)$ & 1 & $(0.4)$ & & \\
\hline BIOL & 358 & $(18.8)$ & 356 & $(99.4)$ & 1 & $(0.3)$ & 1 & $(0.3)$ & & \\
\hline MED & 559 & $(29.3)$ & 556 & $(99.5)$ & 2 & $(0.4)$ & 1 & $(0.2)$ & & \\
\hline SCI & 374 & $(19.6)$ & 366 & (97.9) & 7 & (1.9) & 1 & $(0.3)$ & & \\
\hline $\mathrm{T} \& \mathrm{E}$ & 334 & $(17.5)$ & 321 & $(96.1)$ & 8 & $(2.4)$ & 5 & (1.5) & & \\
\hline Biological $^{b}$ & 1,201 & ( 62.9) & 1,193 & (99.3) & 5 & $(0.4)$ & 3 & $(0.2)$ & 8 & $(0.7)^{\mathrm{d}}$ \\
\hline Chemical $^{\mathrm{c}}$ & 708 & ( 37.1$)$ & 687 & (97.0) & 15 & (2.1) & 6 & (0.8) & 21 & $(3.0)^{\mathrm{d}}$ \\
\hline Total & 1,909 & (100.0) & 1,880 & (98.5) & 20 & (1.0) & 9 & $(0.5)$ & 29 & (1.5) \\
\hline
\end{tabular}

${ }^{\mathrm{a} A s}$ defined by the Regulation (Ref. 7).

${ }^{\mathrm{b}} \mathrm{AGR}+\mathrm{BIOL}+\mathrm{MED}$.

cSCI + T\&E.

${ }^{\mathrm{d}}$ The difference is significant $(p<0.01)$.

cases. Further comparison was conducted by $\chi^{2}$ test after combination of AGR, BIOL and MED into one group of biology-based fields and SCI and T\&E as chemistry-based fields, the risk of being in Classes 2 and 3 was higher $(p<0.01)$ for the chemistry-based group (21 cases out of 708 , or $3.0 \%$ ) than for the biology-based group ( 8 cases out of 1,201 , or $0.7 \%$ ).

\section{Discussion}

The present analyses of air-borne solvent levels in laboratories in four large research institutions revealed that types of solvents commonly used were biased and that only 5 and 28 solvents out of 7 Group 1 solvents and 40 Group 2 solvents were in use even in research institutions. Among the 47 solvents, 10 solvents of acetone, chloroform, dichloromethane, ethyl acetate, ethyl ether, hexane, isopropyl alcohol, methanol, toluene and xylenes were detected in air of more than $10 \%$ of 1,909 laboratories surveyed.

With regard to use pattern, the observation in research laboratories made it clear that use of solvents was unique in the sense that unmixed single solvent was often used in research laboratories. This made a sharp contrast to the use in industries where the use of mixed solvents is quite common although unmixed solvents were also in use ${ }^{6}$. In printing or painting plants, for example, printing inks, thinners and paints usually contain more than one solvent already prior to application in production line so that solvent vapors generated contain two or more solvent components by nature ${ }^{6}$.

From workplace health and safety viewpoints, a majority of laboratories were in Class 1 in Administrative Control Levels (Table 5). Such good results are in general agreement with previous findings ${ }^{15)}$. Nevertheless, the presence of laboratories iden- tified as Class 3 may need detailed analyses. In most cases, the identifications as Class 3 work environment were due to the presence of chloroform vapor at relatively high concentrations (e.g., in excess of $3 \mathrm{ppm}$ ). One example was that chloroform was used as a mobile phase in high pressure liquid chromatography (HPLC). The system was too large to be accommodated in a draft chamber, and the connection between a drain tube and a waste liquid container was not tight enough to prevent vapor emission. In a separate case, chloroform was employed as a solvent for extraction, and a rotary evaporator was applied for condensation of the extract; chloroform vapor leaked during the evaporation process. Improper use of a general exhaust system might have aggravated the hygiene conditions. It appeared likely that the leakage of chloroform vapor from the instruments was difficult to minimize, whereas some instruments were too large to be operated in local exhaust systems. Such difficulties brought in poor hygiene conditions and room environment was identified as Class 3 . These experiences suggest that the best effort should be made to replace chloroform with other less hazardous solvent. Consideration for so-called green analytical chemistry ${ }^{11-14)}$ is especially important in research and teaching institutions where future scientists are in growth. It should be noted that the use of chloroform has been quite limited and seldom observed in industries for years ${ }^{17-19)}$. Chloroform was used also in bio-technology laboratories. The quantity applied there was, however, usually too small to generate vapors at dangerous levels.

There are several limitations in the present study. First of all, solvent vapor sampling and analyses were conducted in accordance to current regulations ${ }^{5)}$ which prescribes 7 and 40 solvents in Group 1 and 2, respectively. Thus, solvents other than these 47 solvents were not identified even if they were used in practice. 
Possible skin absorption was not taken into account, although use of protective gloves was rather rare in laboratories.

There is no rationale to assume that the four research institutions studied can be taken as representative ones. They were all large in size, and large facilities may enjoy better use of local exhaust systems including draft chambers ${ }^{15}$. It is also known that, in enterprises, there is a size-dependent quality of industrial hygiene ${ }^{16)}$. By analogy, it might be the case that smaller laboratories have more difficulties in practice.

Classification of laboratories by research fields is not clear-cut. Application of analytical chemistry, for example, is almost everywhere in natural science in general, and bio-technology is wide-spread tool across the science discipline. Histology preparation with use of xylenes is also common in various laboratories in AGR and BIOL as in MED. Thus, the present classification should be taken as a tentative example.

\section{Acknowledgements}

The authors are grateful to the administration and fellow staff of Kyoto Industrial Health Association for their interest in and support to this work.

\section{Conflicts of interest statement}

The authors declare that they have no conflict of interest.

\section{References}

1) Government of Japan (2006) Industrial Safety and Health Law (Law No. 25; originally enacted in 1972 as Law No. 57) (in Japanese).

2) Government of Japan (2006) Enforcement Order of Industrial Safety and Health Law, Japan (Cabinet Order No. 72, originally enacted in 1972 as Cabinet Order No. 318) (in Japanese).

3) Inadera H, Tsukahara T (2010) Symposium on industrial and occupational health at universities. Sangyo Eiseigaku Zasshi 52 (Suppl) 237-42 (in Japanese).

4) Ohkubo Y, Karima R, Nakata A, Tsukahara T (2006) Establishment of inter-university net-work for occupational health activities. J Occup Health 29, 65-70 (in Japanese).

5) Ministry of Health, Labour and Welfare, Japan (2006) Ordinance for Prevention of Organic Solvent Poisoning. Ministry of Health, Labour and Welfare Ordinance No. 1; originally enacted in 1972 as Ministry of Labour Ordinance No. 36 (in Japanese).

6) Samoto S, Fukui Y, Ukai H, Okamoto S, Takada S, Ohashi F, Moriguchi J, Ezaki T, Ikeda M (2006) Field survey on types of organic solvents used in enterprises of various sizes. Int Arch Occup Environ Health, 79, 558-67.

7) Ministry of Health, Labour and Welfare, Japan (2006) Working Environment Measurement Standards (Ministry of Health, Labour and Welfare Notification No. 44; originally enacted in 1976 as Ministry of Health, Labour and Welfare Notification No. 46) (in Japanese).

8) Ministry of Health, Labour and Welfare, Japan (2006) Working Environment Evaluation Standards (Ministry of Health, Labour and Welfare Notification No. 50; originally enacted in 1988 as Ministry of Health, Labour and Welfare Notification No. 79) (in Japanese).

9) Japan Society for Occupational Health (2009) Recommendation of occupational exposure limits (2009 -2010). J Occup Health 51, 454-70.

10) Japan Association for Working Environment Measurement (1996) Working Environment Measurement System in Japan (3rd Ed.), Japan Association for Working Environment Measurement, Tokyo.

11) Inoue O, Ukai H, Ikeda M (2006) Green chemistry in urinalysis for trichloroethanol and trichloroacetic acid as markers of exposure to chlorinated hydrocarbon solvents. Ind Health 44, 307-14.

12) Anastas PT, Kirchhoff MM (2002) Origins, current status, and future challenges of green chemistry. Acc Chem Res 35, 686-94.

13) Kirchhoff MM (2003) Promoting green engineering through green chemistry. Environ Sci Technol 37, 5349-53.

14) Wang J (2002) Real-time electrochemical monitoring; toward green analytical chemistry. Acc Chem Res 35, 811-6.

15) Takada S, Okamoto S, Yamada C, Ukai H, Samoto H, Ohashi F, Ikeda M (2008) Chemical exposure in research laboratories in a university. Ind Health, 46, 166-73.

16) Ukai H, Ohashi F, Samoto H, Fukui Y, Okamoto S, Moriguchi J, Ezaki T, Takada S, Ikeda M (2006) Relation of average and highest solvent vapor concentrations in workplaces in small to medium enterprises and large enterprises. Ind Health 44, 267-73.

17) Ukai $H$, Inui $S$, Takada $S$, Dendo J, Ogawa J, Isobe K, Ashida T, Tamura M, Tabuki K, Ikeda M (1997) Types of organic solvents used in small- to mediumscale industries in Japan; a nationwide field survey. Int Arch Occup Environ Health 70, 385-92.

18) Samoto S, Fukui Y, Ukai H, Okamoto S, Takada S, Ohashi F, Moriguchi J, Ezaki T, Ikeda M (2006) Field furvey on types of organic solvents used in enterprises of various sizes. Int Arch Occup Environ Health 79, 558-67.

19) Nagasawa $Y$, Ukai $H$, Okamoto $S$, Samoto $H$, Itoh K, Moriguchi J, Sakuragi S, Ohashi F, Takada S, Kawakami T, Ikeda M (2010) Organic solvent use in enterprises in Japan. Ind Health 49, 534-41. 